\title{
How Can Economists and Horticulturists Cooperate on Alternative Crop Research and Development Programs?
}

\author{
Edmund A. Estes ${ }^{1}$ \\ Department of Agricultural and Resource Economics, North Carolina State University, \\ Campus Box 8109, Raleigh, NC 27695-8109
}

American farmers are only now emerging from a half decade of severe economic stress in which many producers experienced higher real borrowing rates, observed declining exports for traditional commodities, saw shrinking farmland values, and participated in record numbers of farm bankruptcies. During this period, many farmers examined new or alternative enterprises to maintain or improve farm income. The search for new or alternative enterprises and the diversification of on-farm product mixes are not new experiences for most U.S. farmers because competitive market pressures require them to examine their practices constantly. Economic pressures have

${ }^{1}$ Professor. also dictated that farmers adjust quickly to advances in technology and react decisively to changes in regulations, resource availability, government programs, and consumer purchase patterns.

New and traditional crop producers have examined high income potential opportunities offered by the production of horticultural and specialty crops. A 1986 survey by Estes and Ingram (1990) of 44 research and extension personnel located in 14 southern states found that 40 of 80 on-going alternative agriculture investigations focused on fruit, vegetable, and specialty crop potential. In most cases, project objectives were to identify potentially useful crops for their area and to determine production and marketing limitations for the crop. Typically, lack of market access and uncertainty about market 
demand were identified as the most limiting factors to rapid expansion of horticultural production.

The process of examining alternative horticultural crop potential has started typically with a determination of production capabilities followed by a market assessment evaluation. While this approach offers a reasonable method of examining alternative crop potential, another approach would be first to conduct market research on changing consumer purchase patterns and then ascertain a grower's capability to supply this product on a market-competitive basis. This second approach suggests that production research should be guided by marketing and economic factors and that alternative crop research should be interdisciplinary. The purpose of this paper is to identify areas of opportunity for interdisciplinary research programs between horticulturists and economists, discuss some common problems resulting from interdisciplinary research, and suggest methods to improve alternative crop evaluations so that results will be useful for growers.

\section{PROBLEM IDENTIFICATION}

U.S. agriculture is dynamic in the sense that it is always changing, but it is also constant in at least two ways: a) farms must be operated as businesses and make a profit; and b) to do so, farmers must identify their best activities, that is, find their comparative and competitive advantages (Estes, 1989). Comparative advantage may be thought of as an internal farm measure to indicate those activities that a farmer is relatively good at doing given certain skills, abilities, interests, and resources. Competitive advantage is an external measure of performance as judged by the marketplace; that is, is a grower better at doing some crop activity than all or some competitors? Frequently, the price received by a farmer for output is a summary indicator of competitive performance. An individual grower should initially determine his on-farm comparative advantage and then estimate if this comparative advantage is sufficient to generate a competitive advantage.

A good way to measure grower internal and external competitiveness is through use of the concept of opportunity cost. In its simplest terms, this is a measure of what a farmer is giving up to do another activity. For example, if a grower raises fall broccoli, then field corn cannot be grown on the same land (usually) and the income from field corn is forgone. While this concept is somewhat abstract, it has practical value since it can provide a farmer with some insight concerning the profit potential for several alternative crops relative to the current mix of products grown. Through a series of simultaneous or sequentially paired crop income comparisons, the farmer has an estimate of the mix of crops that will provide the largest net income given certain resource limitations.

To measure opportunity costs for a particular farm operation, reasonable estimates of gross revenue and costs are needed for each crop to be considered. These figures are, of course, the key elements in providing a measure of the farm's income. Estimating net income is straightforward and involves calculating fixed and variable costs, finding published yields and market prices for comparable quality during the anticipated harvest time, estimating cash flow and financial requirements over the season, and establishing buyer contacts in the market. Of course, realization of a profit is much more difficult than identifying a set of possible income opportunities on paper. However, estimation of paper profits is a useful and necessary planning exercise before crops are planted.

Beyond profit planning, supplemental screening aids, such as conversations with intermediate handlers, brokers, extension agents, as well as competitors, general awareness of changing trends in consumer tastes and preferences, and examination of niche time slots in markets through market window techniques should be used to help identify possible alternatives. Consideration of all these factors plus personal preferences should reduce the number of possible alternatives to a smaller, workable subset of crops. Use of only one tool, such as market windows, cannot determine the advisability and feasibility of an alternative, but collectively these aids can provide sufficient information concerning the likelihood of generating a profit from each alternative.

For horticultural crops, it rarely makes sense to grow a crop without developing a detailed marketing plan that considers how, when, and where the product is to be sold. Farmers who possess a competitive production and/or marketing advantage have the greatest potential for profits in any given situation. Assessment of a grower's competitive advantage requires determination of comparative production and marketing advantages, better use of inputs, and experimentation with alternative methods of producing and marketing commodities. Alternative activites will look most attractive to growers who have little prospect for profits in the traditional enterprises because their opportunity cost (think of opportunity cost as a single measure that considers both comparative and competitive advantages) of switching practices or commodities will be less. Understanding and use of multiple economic assessment tools such as market windows, enterprise budgets, opportunity cost comparisons, and linear programming can help farmers make better choices among a variety of economic-based decisions.

The above economic factors, however, cannot be considered apart from the cultural and technical information available from field horticulturists. Recommendations to growers based only on economic and marketing considerations are insufficient. Interdisciplinary cooperation is necessary if informed and appropriate decisions are to be made. As a final factor, all researchers should consider the entrepreneurial skills of individual farmers. Alternative crop production and marketing will require grower foresight, imagination, determination, and superior management and selling skills. These factors are difficult to teach, but seem necessary for success in alternative crops. Before suggesting an alternative crop, it may be useful to rate a grower's entrepreneurial and management skills and select only those individuals or families who rate highest in these categories.

\section{PROGRAM INITIATION}

Since the basic premise motivating alternative crop investigations is to discover systems or commodities that offer greater profit and income potential than current activities, there should be an identifiable advantage that a region or farmer possesses before additional research and extension efforts in the alternative commodity are warranted. Identification of possible competitive advantages for a region is an activity where an agricultural economist can assist horticulturists and farmers. Economists can use on-farm records, field research data, and crop prices in a linear programming package to suggest an optimal hectarage for each crop to plant as well as suggest an appropriate mix of crops to grow to increase total farm income. At North Carolina State Univ., an easy-to-use linear programming package for noneconomists is available and is called Crop Planner (Estes et al., 1990). For linear programming models, less variability in crop yield and greater certainty in input requirements will result in greater confidence and reliability in programming model recommendations.

An economist can also use model results to suggest an appropriate crop sales strategy. If a grower can manage resources better than most competitors, as measured by production costs, then a recommended sales strategy would be to focus on the low per unit cost aspect when talking to buyers. Profits are realized because of a producer's ability to manage resources better than his competitors. This approach is reasonable for high-consumption commodities such as potatoes, tomatoes, and apples because buyers purchase quantities frequently, and often market access is secured only through lower-than-average prices. This operating principle is often employed in agronomic crop sales, but it can be used for traditional horticultural crops as well.

A second sales approach would be to identify and provide products for timed, or niche, markets, where there are fewer suppliers and growers could capture a larger market share. For timing markets, earlier- or later-than-normal harvest periods create sales opportunities rather than volume or cost factors. Summer broccoli and muskmelons in the mountains of North Carolina are successful examples of this strategy. While it is still necessary to be an efficient producer if a grower uses this approach, profits are generated because of the innovative entrepreneurial skills of the grower and as reward for taking additional risks. Lacking clear advantage in either 
lower costs per unit or niche access, a third strategy would be to offer value added to the buyer. For horticultural crops, adoption of a value-added strategy means that a farmer is trying to move beyond the sale of a "commodity" to the sale of a commodity and an associated set of services. Services could include pre-cooling, dependable and more frequent deliveries, and tighter grading of products than provided by competitors. Forced-air cooling of bell peppers, used in combination with intensive cultural practices, were strategies used by North Carolina growers to obtain access to new markets and expand production. The use of brand names on boxes to differentiate quality is also a form of offering additional services to the buyer with little added expense. Driscoll strawberries and 'Sun World' red and yellow peppers are successful examples of this strategy. A recent variation of moving beyond the sale of only a commodity involves the identification of organically grown produce where the producer and retailer are selling food safety as well as product.

\section{THE DILEMMA OF INTERDISCIPLINARY COOPERATION}

Involvement of agricultural economists in evaluating the potential of an alternative crop is critical since they can provide vital feasibility information and can offer a unique perspective on likely competitive pressures. However, several problems usually arise during the initial work planning period. First, economists often view this cooperative effort as more "service" work rather than "cooperative research." This perception is pervasive among economists because it is unlikely that reports will result in a journal article. For example, since 1980 there have been $\approx 600$ articles published in the American Journal of Agricultural Economics (AJAE), but only eight, or $\approx 0.1 \%$, have focused primarily on fruit or vegetable production in the United States. Indeed, a majority of the eight articles examined primarily labor or trade issues associated with perishable crops rather than mainstream farm management and marketing topics. In many cases, this publication record is justified because the topic or the research approach was of little interest to the general $A J A E$ readership. While there are other publication outlets and alternative journals, this reality can sometimes mitigate enthusiasm for cooperating on a project. The opportunity for economic research (as opposed to cooperating on a horticultural research topic that could use some economic interpretation) must exist before an economist will cooperate on a project.

Second, some horticulturists involve an economist only after the data are collected and they dump the computer printout on the economist's desk and want it analyzed from an "economic perspective." Obviously, this approach limits what an economist can and would want to do. Alternatively, an economist may view the horticulturist only as a source for primary data and has little interest in examining issues of concern to a producer or horticulturist. Improved cooperation can result only if an economist is involved in the initial planning phase and the experimental design of the project so that appropriate economic data can be obtained. This approach provides an incentive for the economist to go beyond the data analysis phase of the project and to do work of economic interest.

A third point is to recognize the distinction between an economic researcher and a business marketing researcher. Frequently, horticultural researchers want business marketing recommendations and/ or analysis from an economist. Economists differ from marketing investigators in terms of methodology used, variables considered, and research focus. Economists often study market equilibrium effects that might result from the interaction of a group of farms and a set of consumers, while marketers would focus primarily on the consumer side of the market. In other words, economists rely on economic theory to examine aggregate grower behavior, while business marketers look at case studies and their previous experience to formulate recommendations for an individual producer.

Economists want to examine effects from price changes while marketers frequently focus on the impact of nonprice variables such as advertising, promotion, and sales. An economist is trained in decision-making rules contained in economic theory, but is unfamiliar with selling and display techniques, advertising and product promotion methods, and product characteristics. Finally, many economists are interested in understanding farmer behavior only to develop public policy implications, while marketers are interested in developing a recommendation of a course of action for a specific situation and farmer. It is useful for horticultural researchers and extension specialists to recognize this distinction in responsibilities and interests between these two research approaches. They may want or need to involve both an agricultural economist and a business marketer in their alternative crop investigation. Finally, the management interests and entrepreneurial skills of a farmer must be considered before suggesting a new or alternative crop. While this factor is somewhat intangible and is often overlooked, it is an important behavioral consideration to an economist. Do you really want to involve this farmer in a system that requires greater attention to production practices and marketing than has been experienced previously? What are the reasons that this crop has not been grown before? Does the grower have a reasonable chance for success given the uncertain markets? Can this grower afford to fail? Alternative crops are not a panacea for financial difficulties and can make matters worse.

\section{IMPLEMENTATION OF NEW INFORMATION}

Typically, alternative crop economic research results are difficult for growers to interpret, understand, and therefore to use. In part, this may be because economists typically do not recommend explicit courses of action but rather outline options and consequences of these actions. This orientation means that economists frequently cannot answer the obvious question of what a grower should do. In addition, economists are loathe to promote the potential of a new crop because of the inexact nature of their analysis (assumptions used, omitted considerations, etc.). A nagging question for some economists is, "If it is such a good idea, why aren't other farmers in the area doing it?" Horticulturists can provide insights and explanations that can assist economists in answering this question.

Finally, it is probably advisable to have a broker or buyer rather than a marketing economist discuss with growers specific marketing requirements associated with an alternative crop. Frequently, specific information needed by growers can be given only by individuals who participate actively in the market. It is particularly important for buyers to participate in county or regional meetings because market uncertainties and price risks are much greater for alternative enterprises and university economists may not have a full appreciation of all the problems and limitations.

\section{SUMMARY}

Interdisciplinary cooperation among marketing economists, business marketers, produce buyers, and horticulturists is necessary to provide sufficient information to growers in evaluating alternative crop opportunities. Growers must identify their comparative and competitive advantages before determining if alternative crops offer a better income potential than current activities. Growers who have low opportunity costs and high management skills are likely candidates to experiment with alternative crops and ultimately realize a profit. A multitude of tools ranging from market window evaluations to linear programming models should be employed to provide sufficient information to growers concerning the advisability of alternative crop production. Farmers must be willing to take risks, however, if they are to realize a profit from alternative crops. It is our collective job to assist them in balancing the risk of losses with the potential for profit by providing timely, accurate, and complete information on all aspects of the production and marketing system.

\section{Literature Cited}

Estes, E.A. 1989. Management tools for increasing profitability. N.C. Agr. Ext. Serv. Publ. AG-418.

Estes, E.A. and D.L. Ingram. 1990. A perspective on alternative farm opportunities in the south. J. Applied Agr. Res. 5(2):89-95.

Estes, E.A., L. Rogers, D. Hoag, and K. Jack. 1990. Crop planner. Microcomputer Farm Management Series no. 3 (revised 1990). Dept. of Economics and Business, N.C. State Univ., Raleigh. 